\title{
MicroRNA-218 enhances gastric cancer cell cisplatin sensitivity by targeting survivin
}

\author{
ZHANDONG ZHANG, YE KONG, WEI YANG, BIN ZHANG, FEI MA, HONGXING LIU and YAWEI HUA \\ Department of General Surgery, Affiliated Tumor Hospital of Zhengzhou University, \\ Henan Cancer Hospital, Zhengzhou, Henan 450008, P.R. China
}

Received January 30, 2018; Accepted June 8, 2018

DOI: $10.3892 /$ etm.2018.6802

\begin{abstract}
Gastric cancer (GC) is one of the most prevalent types of cancer worldwide. Cisplatin based chemotherapy is the primary strategy implemented for the treatment of G; however, chemoresistance is a major problem. Previous studies have indicated that microRNAs (miRs) are associated with chemoresistance in various types of cancer and that miR-218 specifically, serves important roles in the growth of GC cells. The present study assessed the potential biological roles of miR-218 in GC cell cisplatin (DDP) resistance. The results obtained from a polymerase chain reaction assay indicated that the expression of miR-218 was decreased in cisplatin resistant SGC7901/DDP cells compared with SGC7901 cells. Furthermore, MTT results indicated that the upregulation of miR-218 expression significantly enhanced SGC7901/DDP cell sensitivity to DDP. The results of a dual-luciferase assay indicated that survivin was a direct target gene of miR-218. Results also demonstrated that miR-218 was overexpressed in SGC7901/DDP cells and that the downregulation of survivin expression enhanced SGC7901/DDP cell sensitivity to DDP. Further study demonstrated that the upregulation of miR-218 decreased the expression of survivin in SGC7901/DDP cells and induced apoptosis. The findings of the present study indicated that the induction of miR-218 enhanced GC cell DDP resistance via the regulation of survivin, which may potentially benefit the clinical treatment of GC in the future.
\end{abstract}

\section{Introduction}

Gastric cancer (GC) has one of the highest mortality rates of all types of cancer, as most patients are diagnosed at an advanced stage $(1,2)$. The highest mortality rate of males and females was $28.3 \%$ in Korea and $10.8 \%$ in Ecuador,

Correspondence to: Dr Yawei Hua, Department of General Surgery, Affiliated Tumor Hospital of Zhengzhou University, Henan Cancer Hospital, 127 Dongming Road, Zhengzhou, Henan 450008, P.R. China

E-mail: yaweih@yeah.net

Key words: microRNA-218, SGC7901, SCG7901/DDP, cisplatin sensitivity, survivin respectively (3). Cisplatin (DDP)-based chemotherapy remains the primary strategy for the treatment of GC; however, DDP resistance is a major problem (4-6). Several factors contribute to chemotherapeutic resistance, including genetic or epigenetic changes in cancer cells (7). Previous studies have indicated that the primary cause of resistance is the overexpression of energy dependent transporters, including P-glycoprotein and multidrug resistance-associated protein, which eject antitumor drugs out of cancer cells $(8,9)$. Further studies have also demonstrated that a defect in drug-induced cancer cell apoptosis was another cause $(8,9)$. The clinical use of DDP-based chemotherapy is thus limited by resistance, meaning that continuous and multiple DDP treatments may lead to various side effects, including renal impairment, neurotoxicity and ototoxicity (10). Therefore, improving the sensitivity of GC cells to DDP may increase the effectiveness of GC treatment.

It is well-established that microRNAs (miRNAs miRs) are a class of small non-coding RNAs, comprised of 18-24 nucleotides, which regulate gene expression by binding to target mRNAs (11). It has been previously demonstrated that miRNAs are abnormally expressed in various types of cancer (12-14): Aberrant miRNAs regulate cancer cell differentiation, proliferation, survival and apoptosis (15). Previous studies have also demonstrated that miRNAs regulate anti-cancer drug resistance (16). Therefore, the present study hypothesized that the combination of miRNA regulation and chemotherapy may serve important roles in the treatment of certain types of cancer. A number of previous studies have indicated that miR-218 is downregulated in many types of cancer, including lung cancer, prostate cancer, cervical carcinoma and GC (17-20). However the association between miR-218 and DDP resistance in GC is yet to be fully elucidated.

The present study demonstrated that the expression of miR-218 decreased significantly in DDP-resistant human GC SGC7901/DDP cells and the induction of miR-218 regulated DDP sensitivity in SGC7901/DDP cells by targeting survivin. The results of the current study may help to resolve the issue of DDP resistance in the clinical treatment of GC in the future.

\section{Materials and methods}

Cell culture. The human gastric adeno-carcinoma cell line SGC7901 was purchased from the Shanghai Yansheng Industrial Co., Ltd. (Shanghai, China) and DDP-resistant 
SGC7901/DDP cells were purchased from Nanjing KeyGen Biotech Co., Ltd. (Nanjing, China). GC cells were cultured in RPMI-1640 medium supplemented with $10 \%$ fetal bovine serum (FBS), $100 \mathrm{IU} / \mathrm{ml}$ penicillin and $100 \mathrm{IU} / \mathrm{ml}$ streptomycin (Gibco; Thermo Fisher Scientific, Inc.). In order to maintain the DDP resistant phenotype, SGC7901/DDP cells were cultured for 1 week at $37^{\circ} \mathrm{C}$ in medium supplemented with $1 \mu \mathrm{g} / \mathrm{ml}$ DDP (Sigma-Aldrich; Merck KGaA, Darmstadt, Germany) and then cultured in medium without DDP for 1 week prior to the study.

Reverse transcription-quantitative polymerase chain reaction $(R T-q P C R)$ analysis of $m i R-218$. Following SGC7901 and SGC7901/DDP cell culture and harvesting, total RNA was extracted from the cells using TRIzol reagent (Invitrogen; Thermo Fisher Scientific, Inc.) according to the manufacturer's protocol. Extracted RNA was then reverse transcribed into cDNA using a TaqMan ${ }^{\mathrm{TM}}$ MicroRNA Reverse Transcription kit (cat.no. 4366596; Applied Biosystems; Thermo Fisher Scientific, Inc.). The temperature protocol of reverse transcription was $16^{\circ} \mathrm{C}$ for $30 \mathrm{~min}$, followed by $42^{\circ} \mathrm{C}$ for $30 \mathrm{~min}$ and $85^{\circ} \mathrm{C}$ for 5 min. miR-218 qPCR was performed using a TaqMan miRNA assay kit (cat. no. 4426961; Applied Biosystems; Thermo Fisher Scientific, Inc.) according to the manufacturer's protocol and as previously described (21).U6RNA was used as an internal control (cat. no. 4351372; Applied Biosystems; Thermo Fisher Scientific, Inc.). The $2^{-\Delta \Delta C q}$ method was used to evaluate the relative expression of miR-218 in GC cells (22).

Transfection. SGC7901 and SGC7901/DDP cells were seeded into 6-well plates $(2,000,000$ cells/well) in RPMI-1640 medium supplemented with $10 \% \mathrm{FBS}$ for $24 \mathrm{~h}$ at $37^{\circ} \mathrm{C}$. The miR-218 inhibitor (100 nM; cat. no. 4464084; Thermo Fisher Scientific, Inc.) or the miRNA inhibitor control (100 nM; cat. no. 4464076; Thermo Fisher Scientific, Inc.) were transfected into SGC7901 cells using Lipofectamine 3000 (Invitrogen; Thermo Fisher Scientific, Inc.) according to the manufacturer's protocol. Additionally, 100 nM miR-218 mimic (cat. no. 4464066; Thermo Fisher Scientific, Inc.) or the miRNA mimic control (cat. no. 4464058; Thermo Fisher Scientific, Inc.) were transfected into SGC7901/DDP cells using Lipofectamine 3000 (Invitrogen; Thermo Fisher Scientific, Inc.) according to the manufacturer's protocol. Survivin small interfering (si)RNA was purchased from Santa Cruz Biotechnology, Inc. (Dallas, TX, USA; cat. no. sc-29499) and the survivin gene knockout assay was performed according to the manufacturer's protocol, untreated cells were used as the control. Following $48 \mathrm{~h}$, samples were used for further experimentation.

Cell viability assay. SGC7901 and SGC7901/DDP cells transfected with miRNA mimics or inhibitors were seeded into 96-well plates (10,000 cells/well). Following cellular adhesion, DDP was added into the cultured cells at concentrations of $0.00,0.03,0.10,0.30,1.00,3.00,10.00,30.00$ and $100.00 \mu \mathrm{g} / \mathrm{ml}$ and incubated for $48 \mathrm{~h}$ at $37^{\circ} \mathrm{C}$. At $48 \mathrm{~h}$ following cell culture, cell viability was evaluated via an MTT assay. MTT solution was added to each well at a concentration of $0.5 \mathrm{mg} / \mathrm{ml}$. DMSO was utilized to dissolve the purple formazan. At $4 \mathrm{~h}$ following MTT incubation at $37^{\circ} \mathrm{C}$, the absorbance at $570 \mathrm{~nm}$ was measured using a microplate reader. A relative survival curve was generated and the half maximal inhibitor concentration
$\left(\mathrm{IC}_{50}\right)$ was defined as the concentration at which DDP inhibited the $50 \%$ cell viability.

MiRNA target predictions. To determine the potential target of miR-218, potential genes were identified using computer-aided algorithms from targetscan (http://www. targetscan.org) and mirbase targets (http://microrna.sanger. ac.uk/cgi-bin/targets/v5/search.pl).

Luciferase assay. The wild type (WT) 3'-untranslated region (UTR) of survivin mRNA (NM_001168, https://www.ncbi. nlm.nih.gov/gene/?term=NM_001168; 5'-CUACAAUUAAAA CUAAGCACAA-3') containing predicted binding sites of miR-218 was amplified from Human Genome DNA by Genewiz (Genewiz, South Plainfield, NJ, USA) and cloned into the downstream region of the firefly luciferase gene in the pMIR-Report reporter vector (Ambion; Thermo Fisher Scientific, Inc.). Mutant (Mut; 5'-CUACAAUUAAAACUUGAGCAGG 3') survivin was used as a control. pGL3-Survivin-3'-UTR and miR-218 mimic or miRNA mimic controls were co-transfected into SGC7901/DDP cells using Lipofectamine 3000 according to the manufacture's protocol. Following transfected cell culture for $48 \mathrm{~h}$ at $37^{\circ} \mathrm{C}$, cells were harvested and submitted to the luciferase assay. The Dual-Luciferase Reporter Assay System was performed according to the manufacture's protocol (cat. no. E1910, Promega Corporation, Madison, WI, USA) and the relative activity was normalized to the expression of Renilla luciferase.

Flow-cytometric analysis of apoptosis. Transfected SGC7901/DDP cells were seeded into 6 well plates (600,000 cells/well). Following cellular adhesion, DDP was added to the cultured cells at a concentration of $10 \mu \mathrm{g} / \mathrm{ml}$. Cells were then cultured at $37^{\circ} \mathrm{C}$ for a further $48 \mathrm{~h}$ and submitted to flow cytometry to determine the relative quantity of apoptotic cells using the Annexin V-FITC Apoptosis Detection kit (cat. no. CA1020; Beijing Solarbio Science \& Technology Co., Ltd., Beijing, China). CellQuest Pro software was used for the analysis of results (Version 5.1; BD Biosciences, Franklin Lakes, NJ, USA)

Western blot analysis. Transfected SGC7901/DDP and SGC7901 cells were seeded in 6 well plates $(600,000$ cells/well) and cultured at $37^{\circ} \mathrm{C}$ for $48 \mathrm{~h}$, after which they were harvested. Protein was extracted using lysis buffer (cat. no. P0013K; Beyotime Institute of Biotechnology, Haimen, China) and protein concentration was measured using a bicinchoninic acid assay. Total protein $(50 \mu \mathrm{g})$ was the separated using $10 \%$ SDS-PAGE gel electrophoresis. Western blotting was performed as previously described (23). The primary antibodies for survivin (1:1,000; cat. no. 2808) and GAPDH (1:2,000; cat. no. 2118) were purchased from Cell Signaling Technology, Inc. (Danvers, MA, USA). GAPDH was used as the internal control. The second antibodies used were horseradish peroxidase labeled-Goat Anti-Rabbit Immunoglobulin G (1:1,000; cat. no. A0208; Beyotime Institute of Biotechnology).

$R T-q P C R$ to detect survivin $m R N A$. Total RNA was isolated from transfected SGC7901/DDP or SGC7901 cells using TRIzol reagent (Invitrogen; Thermo Fisher Scientific, Inc.) 


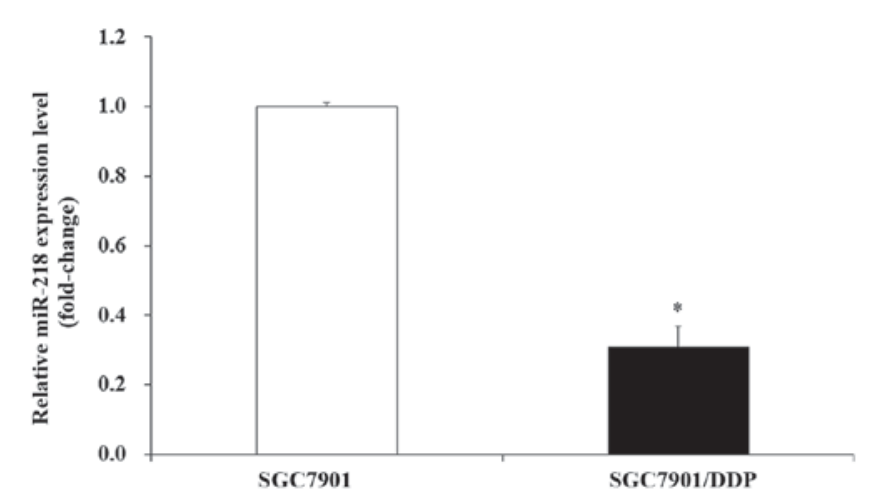

Figure 1. Expression of miR-128 in human GC cell lines. Relative miR-128 levels were measured using a reverse transcription quantitative polymerase chain reaction assay. Data are expressed as the mean + standard deviation. ${ }^{*} \mathrm{P}<0.05$ vs. SGC7901 cells. miR, microRNA; GC, gastric cancer; DDP, cisplatin.

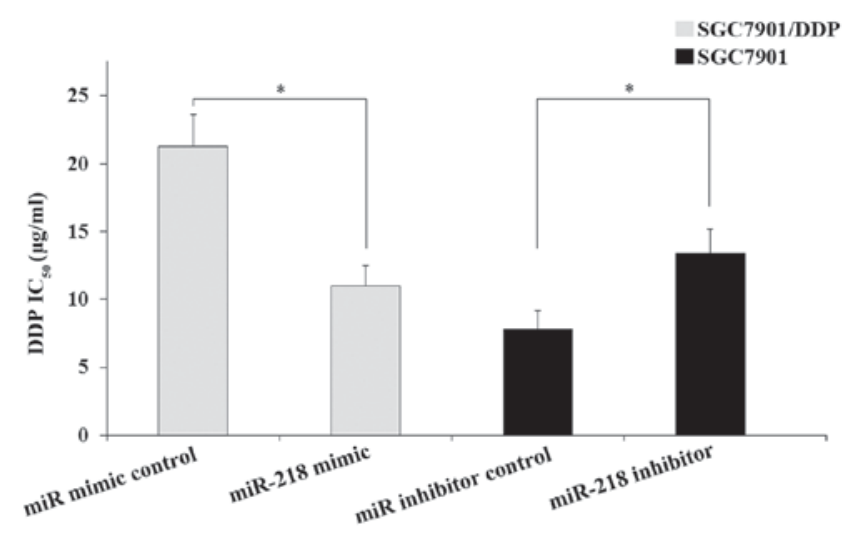

Figure 2. miR-218 regulated GC cell sensitivity to DDP. In SGC7901/DDP cells, an MTT assay revealed that the upregulation of miR-128 significantly decreased resistance to DDP; while in SGC7901 cells, the downregulation of miR-128 significantly enhanced resistance to DDP. Data are expressed as the mean + standard deviation. ${ }^{*} \mathrm{P}<0.05$ vs. respective controls. $\mathrm{miR}$, microRNA; DDP, cisplatin; GC, gastric cancer; $\mathrm{IC}_{50}$, half maximal inhibitor concentration.

in accordance with the manufacturer's protocol. Total RNA $(2 \mu \mathrm{g})$ was reverse transcribed into cDNA using an iScript cDNA synthesis kit (Bio-Rad Laboratories, Inc., Hercules, CA, USA). The temperature protocol for RT was as follows: $5 \mathrm{~min}$ at $25^{\circ} \mathrm{C}$, followed by $30 \mathrm{~min}$ at $42^{\circ} \mathrm{C}$ and $5 \mathrm{~min}$ at $85^{\circ} \mathrm{C}$. qPCR was performed using an LC480 machine (Roche Diagnostics, Basel, Switzerland) using a FastStart Universal SYBR Green Master (cat. no. 04913914001; Roche) and gene-specific primers. The thermocycling conditions were as follows: $95^{\circ} \mathrm{C}$ for $10 \mathrm{~min} ; 95^{\circ} \mathrm{C}$ for $10 \mathrm{sec} ; 57 \mathrm{kC}$ for $20 \mathrm{sec}$ and $72^{\circ} \mathrm{C}$ for $10 \mathrm{sec}$ (40 cycles). The primer sequences utilized were as follows: GAPDH forward, 5'-TCGACAGTCAGCCGC ATCTTCTTT-3' and reverse, 5'-ACCAAATCCGTTGAC TCCGACCTT-3'; and Survivin forward, 5'-GGACCACCG CATCTCTACAT-3' and reverse, 5'-GACAGAAAGGAAAGC GCAAC-3'. Relative transcript expression of survivin relative to GAPDH was determined using the $2^{-\Delta \Delta \mathrm{Cq}}$ method (22).

Statistical analysis. Each experiment was performed in triplicate. The data was expressed as the mean + standard deviation. Statistical analysis was performed using a two-tailed Student's t-test with SPSS 13.0 software (SPSS, Inc., Chicago, IL, USA). $\mathrm{P}<0.05$ was considered to indicate a statistically significant result.

\section{Results}

miR-218 is downregulated in DDP-resistant SGC7901/DDP cells. A previous study has demonstrated that miR-218 is downregulated in gastric cancer cells (24). The present study therefore assessed the expression of miR-218 in the DDP-resistant gastric cancer cell line (SGC7901/DDP) and its mock cell line (SGC7901). RT-qPCR results indicated that the expression of miR-218 was downregulated in DDP-resistant gastric cancer SGC7901/DDP cells compared with SGC7901 cells, with a decreased fold change of $\sim 3.1$ (Fig. 1).

miR-218 modulates DDP resistance in SGC7901/DDP cells. To evaluate the effect of miR-218 on DDP resistance in GC cells, an MTT assay was performed. As presented in Fig. 2, the transfection of miR-218 mimics into SGC7901/DDP cells induced a significant decrease in the $\mathrm{IC}_{50}$ of DDP compared with those cells transfected with the miRNA mimic control $(\mathrm{P}<0.05)$. However, transfection of the miR-218 inhibitor into SGC7901 cells significantly increased the $\mathrm{IC}_{50}$ of DDP compared with those cells transfected with the miRNA inhibitor control $(\mathrm{P}<0.05)$. Therefore, the results demonstrated that miR-218 modulates the DDP resistance of GC cells.

Survivin is the target gene of $m i R-218$. To identify the target gene of miR-218, a search was performed using the microRNA. org database (www.microrna.org). The results indicated that survivin was a potential target gene of miR-218 (Fig. 3A). To confirm this, a dual luciferase assay was performed on SGC7901/DDP cells. WT and Mut survivin 3'-UTR was fused directly downstream of the firefly luciferase gene (Fig. 3A) and then co-transfected with the miR-218 mimic and various luciferase 3'-UTR constructs (WT or Mut) into SGC7901/DDP cells. Transfected cells were then cultured and luciferase activity was measured. The dual luciferase assay results indicated that the enhanced expression of miR-218 significantly decreased luciferase activity in the WT pLuc-Survivin 3'-UTR reporter $(\mathrm{P}<0.05)$. However, no significant difference was observed between cells treated with the miR-218 mimic and cells that received the miRNA mimic control in the Mut pLuc-Survivin 3'-UTR reporter group (Fig. 3B). These results demonstrated that survivin is a direct target gene of miR-218.

Survivin is overexpressed in resistant GC cell lines and is associated with DDP resistance. To assess whether survivin gene expression was associated with DDP resistance, survivin protein and mRNA expression in SGC7901/DDP cells and SGC7901 cells was determined. Western blotting and RT-qPCR results indicated that survivin protein and mRNA expression was increased in SGC7901/DDP cells compared with SGC7901 cells ( $\mathrm{P}<0.05$; Fig. 4A and B). It was further demonstrated that the transfection of survivin siRNA resulted in a significant decrease in DDP IC $_{50}$ in SGC7901/DDP cells compared with the untreated cells $(\mathrm{P}<0.05$; Fig. 4B). The 
A

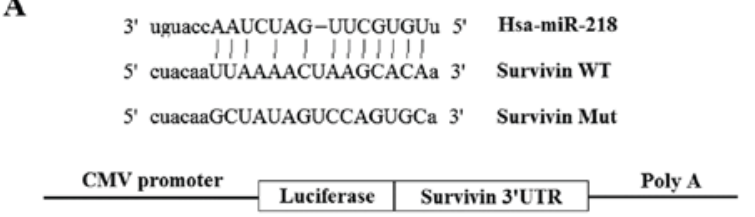

B

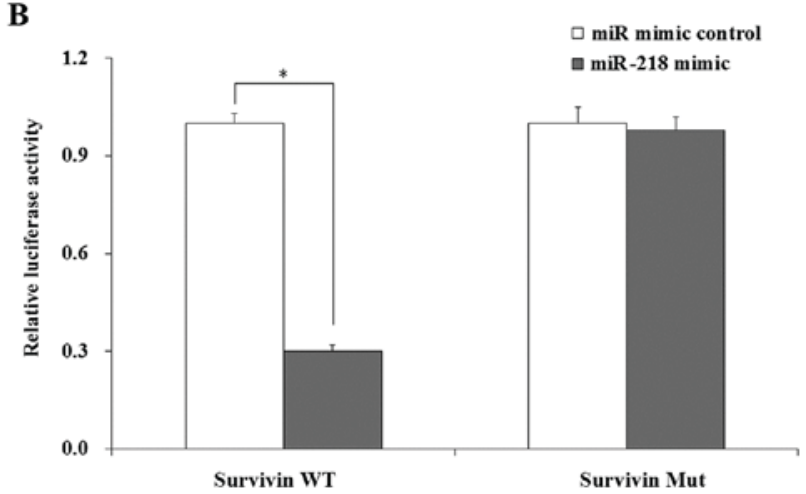

Figure 3. Survivin was a direct target of Hsa-miR-218. (A) Prediction of miR-218 binding sites in the 3'UTRs of the human survivin gene. (B) Survivin was confirmed to be a direct target of Hsa-miR-218 by performing a dual-luciferase assay. Data were expressed as the mean + standard deviation. "P<0.05. miR, microRNA; UTR, untranslated region; WT, wild type; Mut, mutant; CMV, cytomegalovirus.

results indicated that the survivin gene was closely associated with DDP resistance in GC cells.

miR-218 modulates DDP resistance by repressing survivin. In the present study it was demonstrated that miR-218 and survivin expression was decreased and overexpressed, respectively in SGC7901/DDP cells when compared with SGC7901 cells (Figs. 1 and 4A). It was also revealed that survivin was a direct target gene of miR-218 and that it was associated with DDP resistance in GC cells. Therefore, it was hypothesized that miR-218 may regulate DDP resistance in GC cells by modulating the expression of survivin. To confirm this, the expression of survivin in GC cells transfected with miR-218 mimic or inhibitor were assessed. The results indicated that transfection of the miR-218 mimic significantly decreased the expression of survivin in SGC7901/DDP cells compared with those transfected with the miRNA mimic control. Transfection of the miR-218 inhibitor increased the expression of survivin protein and mRNA in SGC7901 cells compared with those transfected with the miRNA inhibitor control (Fig. 5). The results indicated that miR-218 modulates DDP resistance in GC cells through the regulation of survivin expression.

Transfected miR-218 sensitizes SGC7901/DDP cells to DDP by inducing apoptosis. A previous study has indicated that drug resistance in various types of cancer is closely associated with the overexpression of anti-apoptotic proteins, including BCL2, MCL1 and XIAP (25). Since survivin has been demonstrated to be a direct target of miR-218 that is associated with DDP resistance (26), the present study hypothesized that miR-218 may modulate DDP resistance in SGC7901/DDP cells by enhancing the DDP-induced apoptosis of SGC7901/DDP cells. To confirm

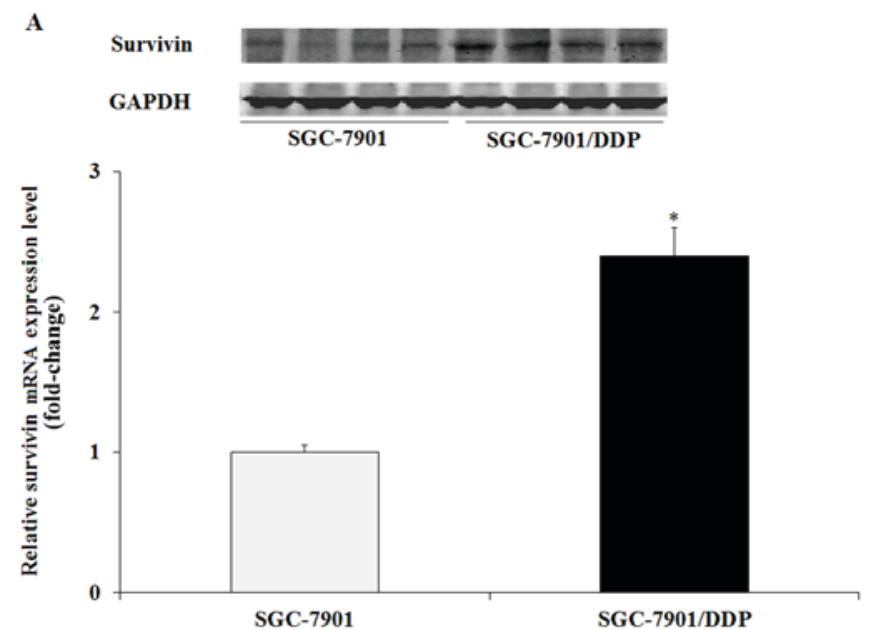

B

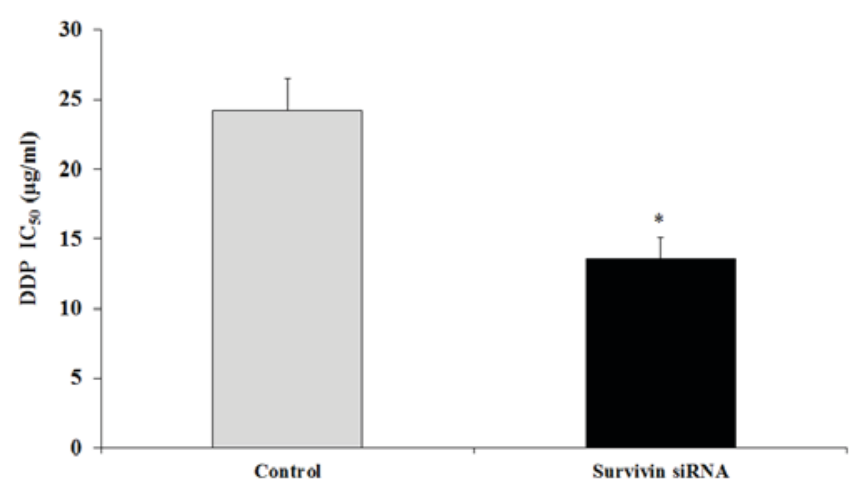

Figure 4. Expression of survivin in resistant GC cell lines and the effect of survivin in GC cell DDP resistance. (A) Survivin levels were measured using western blotting and a reverse transcription-quantitative polymerase chain reaction assay. ${ }^{*} \mathrm{P}<0.05$ vs. SGC-7901. (B) In human GC cells, an MTT assay revealed that the knock out of survivin significantly decreased resistance to DDP. Data were expressed as the mean + standard deviation. ${ }^{*} \mathrm{P}<0.05$ vs. control. GC, gastric cancer; DDP, cisplatin; $\mathrm{IC}_{50}$, half maximal inhibitor concentration; siRNA, small interfering RNA.

this, flow cytometry was performed. The miR-218 mimic or miRNA mimic control was transfected into SGC7901/DDP cells, which were subsequently treated with DDP and cultured. Cells were then harvested and the apoptosis rate was determined. The results indicated that there was a significant induction of apoptosis in SGC7901/DDP cells transfected with the miR-218 mimic compared with those transfected with the miRNA mimic control ( $\mathrm{P}<0.05$; Fig. 6). Therefore miR-218 enhanced the sensitivity of DDP resistance in GC cells by inducing apoptosis, at least in part, by targeting survivin.

\section{Discussion}

Surgery is the primary treatment for early stage gastric cancer; however, the majority of patients are diagnosed at an advanced stage and receive chemotherapy as a primary treatment option (27). Furthermore, DDP-based chemotherapy is the major strategy for the clinical treatment of GC (16). However DDP resistance is an obstacle for effective GC therapy (27). A previous study has demonstrated that miRNA dysregulation is present in many different types of human cancer (28). 
A

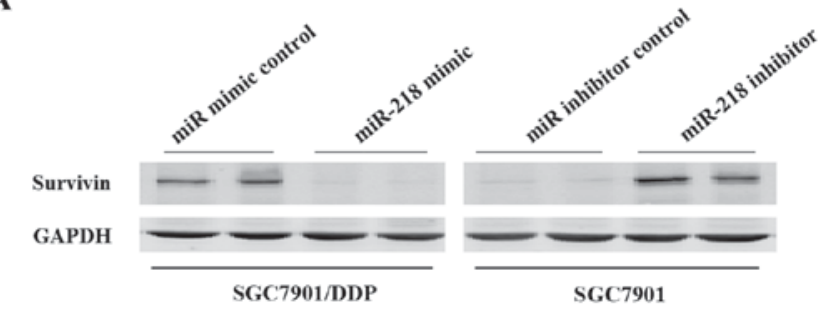

B

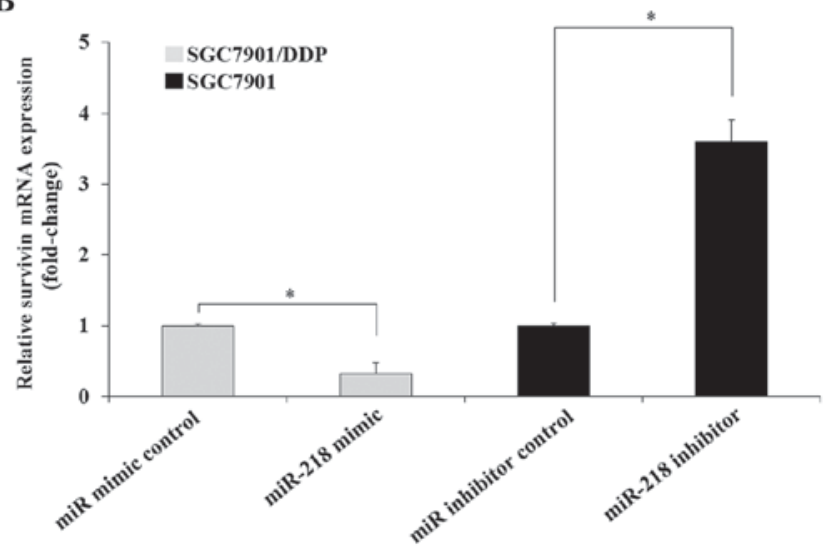

Figure 5. Expression of survivin in human GC cells transfected with an miR-218 mimic or inhibitor. (A) The expression of survivin was measured using western blotting. (B) The expression of survivin was measured using a reverse transcription quantitative polymerase chain reaction assay. Data were expressed as the mean + standard deviation. ${ }^{~} \mathrm{P}<0.05$. GC, gastric cancer; miR, microRNA; DDP, cisplatin.

Other studies have also indicated that certain miRNAs, including miR-128, miR-497 and miR-200, may contribute to chemotherapeutic drug resistance (29-31). A number of previous studies have revealed that miR-218 was downregulated in various malignancies, including colon cancer, cervical cancer and GC. Furthermore, these studies also indicated that miR-218 serves an important biological role in cancer proliferation and metastasis (32-35). However, the functional and biological roles of miR-218 in GC cell chemosensitivity are yet to be fully elucidated.

To investigate the role of miR-218 in GC cell chemosensitivity, the present study assessed the expression of miR-218 in DDP resistant GC SGC7901/DDP cells. The results of RT-qPCR demonstrated that the expression of miR-218 was significantly downregulated in SGC7901/DDP cells compared with SGC7901 cells. Further assessment revealed that the upregulation of miR-218 sensitized SGC7901/DDP cells to DDP via the inhibition of cell viability and the induction of cell apoptosis.

Survivin is encoded by Baculoviral inhibitor of apoptosis repeat containing 5 and is a member of the apoptosis inhibitor family (31). Survivin may therefore serve anti-apoptotic roles in cells due to its regulation of caspase activity (36). It has also been demonstrated that survivin exhibits an anti-apoptotic role via the inhibition of caspase-9 activity, which is associated with the hepatitis B X-interacting protein (37). These studies have also indicated that survivin serves an important role in antitumor drug resistance and may therefore be a promising biomarker of antitumor drug resistance $(37,38)$.
A
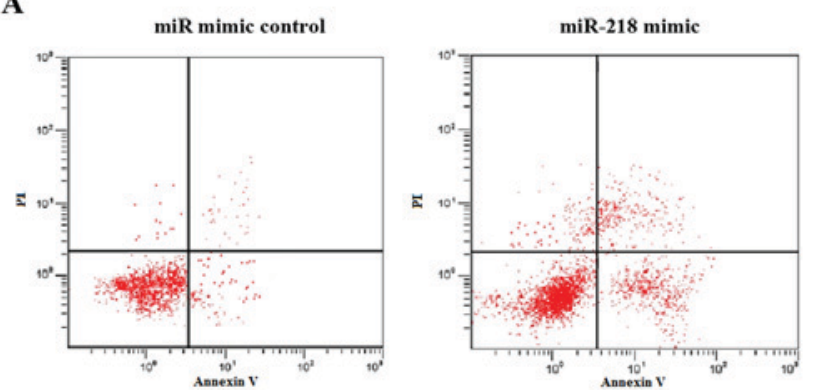

B

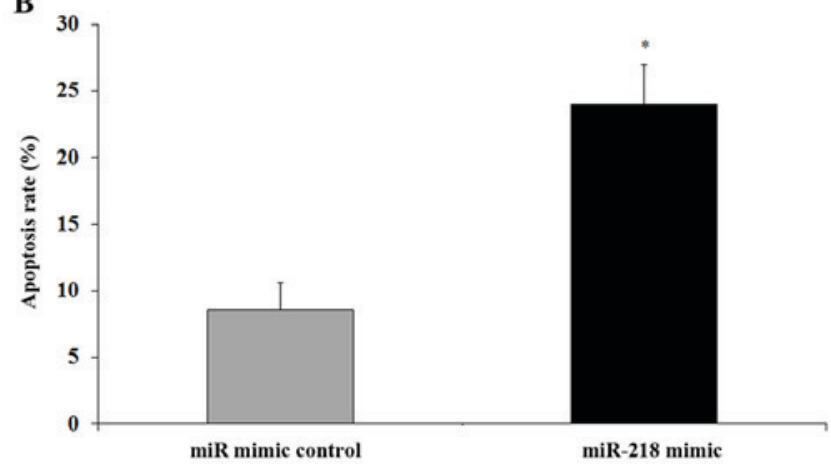

Figure 6. SGC7901/DDP cells treated with miR-218 were sensitized to DDP-induced apoptosis. (A) In SGC7901/DDP cells, apoptosis was assessed using flow cytometry. (B) Representative results of flow cytometry. Data were expressed as the mean + standard deviation. ${ }^{~} \mathrm{P}<0.05$ vs. the miRNA mimic control. DDP, cisplatin; miR, microRNA; PI, propidium iodide; FITC fluorescein isothiocyanate.

A previous study has indicated that dysregulated survivin is associated with many types of human cancer, including breast and lung cancer, as well as prostate, gastric, colon, bladder and esophageal carcinoma, osteosarcoma, and lymphoma (39). A previous study has also indicated that certain survivin-targeting miRNAs have been identified in many types of cancer (40). The present study demonstrated that survivin is a direct target gene of miR-218. It was also revealed that survivin protein and mRNA expression was increased in DDP resistant GC SGC7901/DDP cells and that decreased survivin expression sensitized GC cells to DDP. Further experiments demonstrated that the transfection of the miR-218 mimic inhibited the expression of survivin in GC cells, whereas the transfection of the miR-218 inhibitor led to the increase of survivin expression in GC cells, which was associated with the induction of cell apoptosis.

Taken together, the present findings demonstrated that miR-218 may be associated with the development of DDP resistance in human GC cells, at least in part, by targeting survivin. The results indicated that the regulation of miR-218 in combination with DDP chemotherapy may provide a novel treatment for human GC in the future.

\section{Acknowledgements}

Not applicable.

\section{Funding}

No funding was received. 


\section{Availability of data and materials}

The datasets used and/or analyzed during the current study are available from the corresponding author on reasonable request.

\section{Authors' contributions}

ZZ, YK and YH designed the present study; WY, BZ, FM and HL performed the experiments; WY, BZ and FM analyzed the data; BZ, FM and HL prepared the manuscript; and ZZ and FM reviewed the manuscript. All authors read and approved the final manuscript.

\section{Ethics approval and consent to participate}

Not applicable.

\section{Patient consent for publication}

Not applicable.

\section{Competing interests}

The authors declare that they have no competing interests.

\section{Authors' information}

\section{References}

1. Ferlay J, Soerjomataram I, Dikshit R, Eser S, Mathers C, Rebelo M, Parkin DM, Forman D and Bray F: Cancer incidence and mortality worldwide: Sources, methods and major patterns in GLOBOCAN 2012. Int J Cancer 136: E359-E386, 2015.

2. Roder DM: The epidemiology of gastric cancer. Gastric Cancer 5 (Suppl 1): S5-S11, 2002.

3. Torre LA, Siegel RL, Ward EM and Jemal A: Global cancer incidence and mortality rates and Trends-an update. Cancer Epidemiol Biomarkers Prev 25: 16-27, 2016.

4. Mesner PW Jr, Budihardjo II and Kaufmann SH: Chemotherapy-induced apoptosis. Adv Pharmacol 41: 461-499, 1997.

5. Kaufmann SH and Earnshaw WC: Induction of apoptosis by cancer chemotherapy. Exp Cell Res 256: 42-49, 2000.

6. Hannun YA: Apoptosis and the dilemma of cancer chemotherapy. Blood 89: 1845-1853, 1997

7. SharmaSV,LeeDY,LiB,QuinlanMP,TakahashiF,MaheswaranS, McDermott U, Azizian N, Zou L, Fischbach MA, et al: A chromatin-mediated reversible drug-tolerant state in cancer cel subpopulations. Cell 141: 69-80, 2010.

8. Rabik CA and Dolan ME: Molecular mechanisms of resistance and toxicity associated with platinating agents. Cancer Treat Rev 33: 9-23, 2007.

9. Johnstone RW, Ruefli AA and Lowe SW: Apoptosis: A link between cancer genetics and chemotherapy. Cell 108: 153-164, 2002.

10. Kostova I: Platinum complexes as anticancer agents. Recent Pat Anticancer Drug Discov 1: 1-22, 2006.

11. Lee RC, Feinbaum RL and Ambros V: The C. elegans heterochronic gene lin-4 encodes small RNAs with antisense complementarity to lin-14. Cell 75: 843-854, 1993.

12. Ma L, Teruya Feldstein J and Weinberg RA: Tumour invasion and metastasis initiated by microRNA-10b in breast cancer. Nature 449: 682-688, 2007.

13. Ma L, Reinhardt F, Pan E, Soutschek J, Bhat B, Marcusson EG, Teruya-Feldstein J, Bell GW and Weinberg RA: Therapeutic silencing of mir-10b inhibits metastasis in a mouse mammary tumor model. Nat Biotechnol 28: 341-347, 2010.

14. Cho WC: MicroRNAs: Potential biomarkers for cancer diagnosis, prognosis and targets for therapy. Int J Biochem Cell Biol 42: $1273-1281,2010$
15. Hummel R, Hussey DJ and Haier J: MicroRNAs: Predictors and modifiers of chemo and radiotherapy in different tumour types. Eur J Cancer 46: 298-311, 2010.

16. Cunningham D, Allum WH, Stenning SP, Thompson JN, Van de Velde CJ, Nicolson M, Scarffe JH, Lofts FJ, Falk SJ, Iveson TJ, et al: Perioperative chemotherapy versus surgery alone for resectable gastroesophageal cancer. N Engl J Med 355: 11-20, 2006.

17. Volinia S, Calin GA, Liu CG, Ambs S, Cimmino A, Petrocca F, Visone R, Iorio M, Roldo C, Ferracin M, et al: A microRNA expression signature of human solid tumors defines cancer gene targets. Proc Natl Acad Sci USA 103: 2257-2261, 2006.

18. Martinez I, Gardiner AS, Board KF, Monzon FA, Edwards RP and Khan SA: Human papillomavirus type 16 reduces the expression of microRNA-218 in cervical carcinoma cells. Oncogene 27: 2575-2582, 2008.

19. Petrocca F, Visone R, Onelli MR, Shah MH, Nicoloso MS, de Martino I, Iliopoulos D, Pilozzi E, Liu CG, Negrini M, et al: E2F1-regulated microRNAs impair TGFbeta-dependent cell-cycle arrest and apopto-sis in gastric cancer. Cancer Cell 13: 272-286, 2008.

20. Yanaihara N, Caplen N, Bowman E, Seike M, Kumamoto K, Yi M, Stephens RM, Okamoto A, Yokota J, Tanaka T, et al: Unique microRNA molecular profiles in lung cancer diagnosis and prognosis. Cancer Cell 9: 189-198, 2006.

21. Li Q, Yang Z, Chen M and Liu Y: Downregulation of microRNA-196a enhances the sensitivity of non-small cell lung cancer cells to cisplatin treatment. Int J Mol Med 37: 1067-1074, 2016.

22. Livak KJ and Schmittgen TD: Analysis of relative gene expression data using real-time quantitative PCR and the 2(-Delta Delta C(T)) method. Methods 25: 402-408, 2001.

23. Moriyama M, Tsukamoto Y, Fujiwara M, Kondo G, Nakada C, Baba T, Ishiguro N, Miyazaki A, Nakamura K, Hori N, et al: Identification of a novelhuman ankyrin-repeated protein homologous to CARP. Biochem Biophys Res Commun 285: 715-723, 2001.

24. Wang LL, Wang L, Wang XY, Shang D, Yin SJ, Sun LL and Ji HB: MicroRNA-218 inhibits the proliferation, migration, and invasion and promotes apoptosis of gastric cancer cells by targeting LASP1. Tumour Biol 37: 15241-15252, 2016.

25. Zhu W, Shan X, Wang TS, Shu YQ and Liu P: miR-181b modulates multidrug resistance by targeting BCL2 in human cancer cell lines. Int J Cancer 127: 2520-2529, 2010.

26. Hu Y, Xu K and Yagüe E: miR-218 targets survivin and regulates resistance to chemotherapeutics in breast cancer. Breast Cancer Res Treat 151: 269-280, 2015.

27. Yang SM, Huang C, Li XF, Yu MZ, He Y and Li J: miR-21 confers cisplatin resistance in gastric cancer cells by regulating PTEN. Toxicology 306: 162-168, 2013.

28. Farazi TA, Spitzer JI, Morozov P and Tuschl T: miRNAs in human cancer. J Pathol 223: 102-115, 2011.

29. Zhu Y, Yu F, Jiao Y, Feng J, Tang W, Yao H, Gong C, Chen J, Su F, Zhang Y and Song E: Reduced miR-128 in breast tumor-initiating cells induces chemotherapeutic resistance via Bmi-1 and ABCC5. Clin Cancer Res 17: 7105-7115, 2011.

30. Creevey L, Ryan J, Harvey H, Bray IM, Meehan M, Khan AR and Stallings RL: MicroRNA-497 increases apoptosis in MYCN amplified neuroblastoma cells by targeting the key cell cycle regulator WEE1. Mol Cancer 12: 23, 2013.

31. Chen DQ, Pan BZ, Huang JY, Zhang K, Cui SY, De W, Wang R and Chen LB: HDAC 1/4-mediated silencing of microRNA-200b promotes chemoresistance in human lung adenocarcinoma cells. Oncotarget 5: 3333-3349, 2014

32. He X, Dong Y, Wu CW, Zhao Z, Ng SS, Chan FK, Sung JJ and Yu J: MicroRNA-218 inhibits cell cycle progression and promotes apoptosis in colon cancer by downregulating BMI1 poly-comb ring finger oncogene. Mol Med 18: 1491-1498, 2013.

33. Li J, Ping $\mathrm{Z}$ and Ning H: MiR-218 impairs tumor growth andincreases chemo-sensitivity to cisplatin in cervical cancer. Int J Mol Sci 13: 16053-16064, 2012.

34. Uesugi A, Kozaki K, Tsuruta T, Furuta M, Morita K, Imoto I, Omura $\mathrm{K}$ and Inazawa $\mathrm{J}$ : The tumor suppressive microRNAmiR-218 targets the mTOR component Rictor and inhibits AKTphosphorylation in oral cancer. Cancer Res 71: 5765-5778, 2011.

35. Xin SY, Feng XS, Zhou LQ, Sun JJ, Gao XL and Yao GL: Reduced expression of circulating microRNA-218 in gastric cancer and correlation with tumor invasion and prognosis. World J Gastroenterol 20: 6906-6911, 2014. 
36. Li F, Ambrosini G, Chu EY, Plescia J, Tognin S, Marchisio PC and Altieri DC: Control of apoptosis and mitotic spindle checkpoint by survivin. Nature 396: 580-584, 1998.

37. Marusawa H, Matsuzawa S, Welsh K, Zou H, Armstrong R, Tamm I and Reed JC: HBXIP functions as a cofactor of survivin in apoptosis suppression. EMBO J 22: 2729-2740, 2003.

38. Singh N, Krishnakumar S, Kanwar RK, Cheung CH and Kanwar JR: Clinical aspects for survivin: A crucial molecule for targeting drug-resistant cancers. Drug Discov Today 20: 578-587, 2015 .
39. Waligórska-Stachura J, Jankowska A, Waśko R, Liebert W, Biczysko M, Czarnywojtek A, Baszko-Błaszyk D, Shimek V and Ruchała M: Survivin-prognostic tumor biomarker in human neoplasms-review. Ginekol Pol 83: 537-540, 2012.

40. Huang J, Lyu H, Wang J and Liu B: MicroRNA regulation and therapeutic targeting of survivin in cancer. Am J Cancer Res 5: 20-31, 2014. 